\title{
Hacia la búsqueda de un nuevo orden mundial
}

\section{Tula Sánchez Dominguez}

"... Debemos fortalecer los precarios fundamentos legales de la economia internacional. No es posible un orden justo y un mundo estable, en tanto no se creen las obligaciones y derechos que protejan a los Estados débiles. Desprendamos la cooperación económica del ámbito de la buena voluntad para cristalizarla en el campo del derecho. Traslademos los principios consagrados de solidaridad entre los hombres, a la esfera de las relaciones entre los países $\ldots n^{n}$.

"La demanda de mayor equidad entre las naciones se ha convertido en una demanda, no sólo de que disminuyan las diferencias en los niveles de vida, sino, lo que es aún más importante, de una participación más justa en el poder y en el proceso de adopción de decisiones." 2 .

"En este tiempo de universalismo hablado, proclamado, declamado, en un mundo donde la técnica alcanza un nivel universal tanto para destruir como para construir y producir, la moral de la especie pasa necesariamente por alto los derechos y deberes económicos de los Estados." 3 . 
N EL INICIO del epilogo del presente siglo. la humanidad entera afronta una serie de amenazas y desafíos, retos que ponen a prueba una vez más la naturaleza y la capacidad humana. El siglo $X X$ ha sido testigo de uno de los más grandes triunfos del género humano, el haber demostrado que no sólo es capaz de dominar la naturaleza a través de la tecnología creada a partir de su ingenio. sino que todos los pueblos del mundo son capaces de sentarse a una mesa de negociación en pos de la realización de un diálogo fructifero hacia la consecución de una meta prefijada.

La coyuntura actual nos muestra el triste espectáculo de una serie de sueños frustrados, sueños a los cuales la organización del sistema de la Comunidad Internacional no ha sabido dar respuesta oportuna y rápida. El mundo de hoy es una enorme realidad de extremos e irracionalidad inexplicables: una realidad donde los ideales que fundamentan los documentos históricos, bajo los cuales se creó y organizó el sistema de la Comunidad Internacional, han sido olvidados para dar paso a la primacía de criterios divisionistas y egoístas, basados en una filosofía del poder irracional y por demás negativa.

El mundo de nuestros dias espectó con esperanza, hace once años. la suscripción de documentos históricos en la evolución del sistema de la Comunidad Internacional; documentos que hablaban de la firme voluntad política que inspiraba a los pueblos del mundo por buscar la realización concreta de la justicia económica internacional, a través de la institucionalización del denominado "Nuevo Orden Económico Internacional". Al cabo de estos once años transcurridos, tal vez lo único positivo logrado es el haber fomentado la formación en la opinión pública internacional, de la certidumbre en la necesidad de remodelar de modo urgente las bases y reglas de juego que regulan el orden económico mundial.

La situación de tensión política en muchas zonas subdesarrolladas del mundo, donde los sistemas democráticos y el estado de derecho se ven amenazados por brotes de violencia organizados, que fomentan una desestabilización socio-política a nivel nacional y regional, condicionan el análisis reflexivo que de tales acontecimientos deben realizar la Comunidad Internacional. De todo lo dicho emerge una certeza evidente: En la rafiz de muchos de estos problemas se encuentran los tentáculos del subdesarrollo socio-económico, tentáculos que se entrelazan de modo firme en un círculo vicioso de pobreza. que no deja salida rápida y cierta a condiciones mejores de vida de grandes masas humanas que pugnan por 
alcanzar las condiciones minimas de realización personal que la especie humana merece.

En 1.974 a través del "Plan de Acción para el Establecimiento del Nuevo Orden Económico Internacional" y la dación de "La Carta de Derechos y Deberes Económicos de los Estados", la Organización de las Naciones Unidas realizó el primer paso hacia la institucionalización del Nuevo Orden Económico Internacional. Dicho acontecimiento histórico respondió a los siguientes factores condicionantes:

- La tendencia hacia la universalidad manifestada en el sistema de las relaciones internacionales.

- La creciente interdependencia de hecho entre las naciones.

- La creciente interrelación entre los problemas sectoriales y los cambios en el equilibrio económico mundial.

- El surgimiento de nuevos actores politicos en el escenario mundial como consecuencia del proceso de descolonización operado.

- La presencia sistemática de nuevos actores económicos a nivel mundial, como es el caso de la banca internacional y las empresas transnacionales.

- La profundización del problema del subdesarrollo y el surgimiento del imperativo de la cooperación económica internacional como sistema organizado.

- La manifiesta aparición del POLICENTRISMO y la DISTENSION en el concierto político internacional.

- La creciente aceptación del ESTADO INTERVENCIONISTA en la dirección económica de todo pais, coadyuvando al logro del desarrollo económico.

En dicha ocasión se fijaron los principios básicos que deberían regir el desenvolvimiento de las relaciones internacionales:

- El principio de igualdad soberana basada en el ejercicio de la soberanía como estado de derecho y no en el poder económico y político de que goce un Estado.

- El principio de la Libre Determinación de los Pueblos.

- El deber de la cooperación internacional.

- El derecho a la plena participación efectiva en la solución de todos los problemas de la humanidad por parte de todos los Estados.

- El principio del respeto a la integridad territorial y el derecho de control directo de los recursos naturales.

- La necesidad de regular y supervisar la acción de las empresas transnacionales. 
- Se instaura toda una mística en cuanto a la necesidad de delinear las bases de una estrategia internacional del desarrollo.

Podemos decir, entonces que las bases filosóficas que fundamentaron el nacimiento del N.O.E.L. en el ámbito internacional fueron: La equidad, la igualdad soberana, la interdependencia, el interís común y la cooperación entre todos los Estados. Como significación de este proceso de institucionalización del N.O.E.I. podemos resaltar las siguientes repercusiones juridicas y socio-politicas:

- Establecer los principios de SOLIDARIDAD MUTUA y RESPONSABILIDAD COLECTIVA.

- Otorgarle a la cooperación económica internacional la categoría de INSTITUCION JURIDICA INTERNACIONAL. estableciendo el deber jurídico de cooperación internacional.

- Establecer el principio de la RESPONSABILIDAD SOLIDARIA como base de la filosof ía del desarrollo.

- Distinguir entre el comercio INTERFUNCIONAL y el comercio internacional.

En la actualidad, muchas de las acciones iniciadas en pos de la ejecución del denominado plan de acción para el establecimiento del N.O.E.I. se encuentran en revisión y en proceso de redefinición; ya que no han podido ser realizadas a plenitud. Dicha inercia en las negociaciones internacionales muestra la inoperancia de algunos mecanismos sólo declarativos que no van acompañados de una real voluntad política por parte de los Estados.

Frente al problema de la INSTITUCIONALIDAD DE LOS MERCADOS MUNDIALES, en que muy poco se ha logrado de efectivo, están en funcionamiento sólo mecanismos de carácter burocrático y de coordinación, los cuales han demostrado ser ineficaces para regular los precios en el mercado mundial. A esto hay que agregar que existe una situación de resquebrajamiento en el proceso de unidad de las estrategias de los países subdesarrollados, los cuales no disponen de un planteamiento claro y concreto de negociación frente al bloque de países desarrollados.

También es evidente la falta de voluntad política para negociar por parte de los parises desarrollados y el predominio en los hechos de las estrategias de penetración económica, por parte de las empresas transnacionales, en el proceso de formación de las condiciones y los precios en el mercado mundial. A mi parecer, en este campo es necesaria una acción 
coordinada, fuerte, clara. concreta y cientifica por parte del grupo de paises subdesarrollados.

También se asiste a un proceso nuevo y real de REDESPLIEGUE PRODUCTIVO INTERNACIONAL, como consecuencia de nuevos desarrollos sin precedentes en el ámbito del desarrollo tecnológico. Frente a este problema no existe un proceso definido de institucionalización de las reglas de juego en cuanto al proceso de transferencia de tecnologia y los sistemas de industrialización. A mi parecer, la estrategia que debe poner en marcha el mundo subdesarrollado en este campo es el de adaptarse a las nuevas condiciones de producción del sistema productivo mundial. diseñando estrategias de industrialización y creación de tecnologia, así como transferencia de tecnologia con criterio agresivo y práctico.

Frente al problema de crisis en el orden monetario mundial, la alternativa es inexistente, el camino es sólo uno, urge la reestructuración del sistema monetario y financiero mundial, se necesita negociar en condiciones paritarias nuevas reglas de juego y nueva filosofia, que otorguen por igual el poder de decisión a cada uno de los miembros de la Comunidad Internacional, desterrando, en todo caso, todo tipo de hegemonía por parte de algún país.

En cuanto al problema del FINANCIAMIENTO DEL DESARROLLO, se necesita fortalecer los mecanismos de la cooperación de origen público. Se necesita fortalecer los canales de negociación multilateral. Es urgente darle solución justa al problema de la deuda externa del Tercer Mundo y se deben disenar nuevos criterios en cuanto a la estructura del financiamiento externo del desarrollo.

Frente al proceso danino de la INTERNACIONALIZACION DE LAS POLITICAS ECONOMICAS, impuestas desde vértices externos, con consecuencias de desestabilización y deterioro de los procesos de integración regional, se necesitan acciones decididas, claras y concretas que partan de los gobiernos nacionales y de los bloques de pafises integrados. Para esto es necesario desarrollar una toma de conciencia bien dirigida.

Frente al estancamiento del Diálogo Norte - Sur, es necesario fomentar la movilización de la opinión pública internacional en tomo a la necesidad de una negociación global.

Frente al desafio que plantean las empresas transnacionales, el Derecho debe desplegar todo mecanismo tendiente a la instauración juridica 
y efectiva del denominado Código de Conducta de las Empresas Transnacionales.

El panorama presentado está lleno de desilusiones, desafios y expectativas; mucho falta por hacer y creo que en esta gran tarea América Latina tiene una función determinante, un rol histórico que no puede dejar de cumplir, un rol en el cual el derecho tiene un campo de acción permanente y decisivo. 